\title{
Seife oder Desinfektionsmittel - was schützt besser vor Viren?
}

Gute Handhygiene ist in Zeiten der Coronapandemie so selbstverständlich geworden wie Zähneputzen. Über die beste Methode herrscht jedoch noch keine Einigkeit. Eine Metaanalyse liefert neue Impulse.

Hand aufs Herz: Handhygiene schützt vor Viren. Die beste Methode, wenn man sich die Hände schmutzig gemacht hat, ist umstritten. Für ihre Metaanalyse [1] berücksichtigten Prof. Dr. Tammy Hoffmann von der Bond University in Gold Coast und ihr Team 18 randomisierte Studien. Darin war untersucht worden, wie sich die Übertragung von Atemwegsinfektionen besser verhindern lässt - durch Händewaschen mit Seife oder Desinfektionsmittel. Entweder waren Personen, die eines davon benutzten, mit Kontrollen verglichen worden, die dies nicht taten, oder beide Methoden waren direkt gegenübergestellt worden.

\section{Häufigkeit scheint nicht ausschlag- gebend}

Eine Analyse der drei Vergleichsstudien von Seifenverwendern und Kontrollpersonen lieferte kein signifikantes Ergebnis. Bei den sechs Untersu-

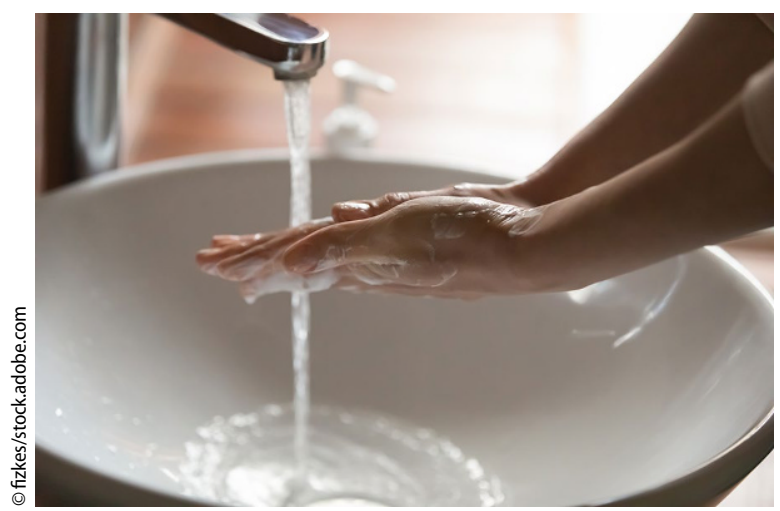

Abb. 1 ॥ Handhygiene verringert das Risiko einer Übertragung von Atemwegsviren (Symbolbild mit Fotomodell) chungen mit Desinfektionsmittelnutzern und Kontrollen zeigte sich jedoch eine signifikante Abnahme des Risikos für Atemwegsinfektionen um $20 \%$ in der Interventionsgruppe. Die Forscher konnten keine klare Dosis-WirkungsBeziehung zwischen der Häufigkeit des Händewaschens oder -desinfizierens und dem Ansteckungsrisiko beobachten.

In vier Studien wurde der Effekt von Desinfektionsmittel und Seife direkt verglichen, sie waren jedoch zu heterogen, um die Ergebnisse zusammenzufassen: In zweien zeigte sich eine signifikant größere Risikoreduktion bei den Personen, die Desinfektionsmittel benutzten, während in den anderen zwei Studien kein signifikanter Unterschied zwischen den Gruppen beobachtet wurde.

\section{Desinfektionsmittel schneidet besser $a b$}

"Angemessen durchgeführte Handhygiene, sowohl mit Seife als auch mit Desinfektionsmittel, verringert das Risiko einer Übertragung von Atemwegsviren. Unsere Ergebnisse weisen darauf hin, dass Desinfektionsmittel die wirksamere Variante sein könnte", lautet das Fazit von Hoffmann und Kollegen. (• Abb. 1) Mögliche Gründe für eine bessere Wirksamkeit von Desinfektionsmittel könnten ihnen zufolge sein, dass es bequemer und schneller benutzt werden kann, dass seine Anwendung besser eingehalten wird und dass es die Haut weniger reizt als Seife.

\section{Das Wichtigste in Kürze}

Schützt der Einsatz von Desinfektionsmittel oder Händewaschen mit Seife besser vor akuten Atemwegsinfektionen?

Beide Arten der Handhygiene verringern das Risiko einer Ansteckung mit respiratorischen Viren, Desinfektionsmittel scheint besser abzuschneiden. Bedeutung: Den Studienautoren zufolge reicht die Evidenz, um den Einsatz von Desinfektionsmittel im Alltag zu fördern.

Einschränkung: Die Schlussfolgerungen basieren hauptsächlich auf indirekter Evidenz und nicht in allen Studien wurde die Dosis-WirkungsBeziehung untersucht.

\section{Literatur}

1. Hoffmann T et al (2021) Soap versus sanitiser for preventing the transmission of acute respiratory infections in the community: a systematic review with meta-analysis and dose-response analysis. BMJ Open 11:e046175. https://doi.org/10.1136/bmjopen-2020-046175

Hinweis des Verlags. Der Verlag bleibt in Hinblick auf geografische Zuordnungen und Gebietsbezeichnungen in veröffentlichten Karten und Institutsadressen neutral.

hautnah $2021 \cdot 20: 188$

https://doi.org/10.1007/s12326-02100480-4

(c) Springer-Verlag GmbH Austria, ein Teil von Springer Nature 2021 